$\left.\begin{array}{c}\text { INTERNATIONAL JOURNAL OF } \\ \text { ORGANIZATIONAL LEADERSHIP }\end{array}\right) \begin{gathered}\text { INDUSTRIAL } \\ \text { MANAGEMENT } \\ \text { INSTITUTE }\end{gathered}$

\title{
Technology commercialization: From generating ideas to creating economic value
}

\author{
Tayeb Dehghani \\ Department of Management and Economics, Bandar Abbas Branch, Islamic Azad University, \\ Bandar Abbas, Iran
}

\begin{abstract}
Keywords:

Commercialization, Technology, Research Outcomes, Customer Needs

Correspondence: Dehghani.tayeb@yahoo.com

Frequent changes in competitors' status, technology, and customer interests make it unwise and impossible for companies to rely on their products. Customers always seek to find new products. Consequently, companies should continuously produce and offer superior products to meet customer needs, tastes, and expectations. In fact, every company needs a development plan for its new products. Research has demonstrated that one of the major reasons for rapid development of technology in industrial countries is commercialization of research results. The basis of such commercialization is research-industry collaboration in converting research output into innovation. Today, technology commercialization and its outcomes can provide financial resources required for organizational longevity. The main objective of this article is to propose a model for commercializing research findings from idea generation to initial market entry. We believe that this article can, hopefully, contribute to commercialization literature by acting as a guide to local authorities involved in commercialization cycle.
\end{abstract}

(C)AIMI Journals

\section{Introduction}

Research on innovation has recently shown a great interest in commercialization. Identification of market demand, investigation for technology development, and commercialization are indispensible parts of creating and developing technology. Moreover, one major cause of fast-growing and improved technology in industrial countries is a good deal of attention devoted to commercialization of research results conducted in such countries. Arguably, inabilities to commercialize, apply research findings in new products 
and processes, and introduce them to market are major drawbacks of developing countries. Rapid changes occur in technology, customer interests, and competitors' status. Therefore, companies attempt to modify their products in accordance with the taste and need of the customers in order to survive and be actively involved in international competition. This requires technology development and commercialization of products in companies. The review of the extant commercialization literature displays concerns that merely 1 or 2 out of 1,000 raw ideas ultimately become commercialized. Also, it is assumed that to build a successful profitable business, creative ideas should be commercialized. As conceptualized in the literature, commercialization is a complex non-linear cycle which necessitates that all involved authorities effectively perform their responsibilities. Lack of financial resources devoted to commercialization which can act as a facilitator and poor access to guidelines to apply research findings took the lead in proposing a commercialization model in this paper.

Commercializing research output proposes directions for future research and, accordingly, provides a catalyst to the knowledge-based economic development of countries. It also brings about economic prosperity and scientific growth which are critical starting points for countries to become a source of knowledge production. Such achievement is feasible through valuing research and its findings as well as achieving an effective interaction of components relevant to national innovation system.

Commercialization process has some key features. Firstly, it is a cycle whereby a given input passes through a series of stages to reach a specific output and in every stage some value is added to it. However, the chain of stages gives the product more added value than the sum of added values at all stages. Secondly, this process, in an attempt to help investors reap benefits, exploits all possible potentials including labor force, organizational structure, rules and regulations, technology, and whatever which deserves to be considered potential. Thirdly, technology commercialization is a necessary part of innovation. If technological innovation is assumed to range from idea generation to initial market entry, there will be no innovation and, thus, no technology without commercialization (Reamer, Icerman, \& Youtie, 2003). Ultimately, the cycle aims at offering benefits to technological innovation investors. This feature is appealing to a vast majority of entrepreneurs and researchers. Accordingly, technology commercialization can be viewed as a help to an idea or innovation in order to reach its market. Therefore, today commercialization is considered a necessary part of innovation chain and the researcher is supposed to generate, nurture, transform, and finally commercialize the good ideas in development stage. The current paper proposed a model for 
commercializing ideas form idea generation to initial market entry. To the best of our knowledge, no such model has been presented before. Hopefully, this model can act as a guide for those involved in commercialization and can shed light on the path to it.

\section{The Literature Review}

Developed countries have a long history in commercialization of ideas and research outputs. For instance, university-industry collaboration in the U. S., concerning linkages between universities and industries in commercialization of innovations and research findings, dates back to decades ago, to the Morril Act of 1862, also known as the Morril Land-Grant acts, defense R \& D during World War II, and competition between two Cold War rivals, the Soviet Union and the U. S.. These are U. S. statutes that allowed for creation of land-grant colleges. In addition, the Bayhe-Dole Act, enacted in law in 1980, encouraged universities to acquire patent government-funded research inventions and to engage with industries in technology transfer and research commercialization (Wu, Welch, \& Huang, 2015).

In today's world, commercialization is one of the most controversial issues. A number of companies and countries give first priority to this issue and allocate their attention among a number of activities. However, even within industrial countries there are some barriers to commercialization such as financial problems, inefficiency of organizational bureaucracy, paucity of research on the influence of organizational strategies and understanding necessary interaction between research teams, lack of mass production, evaluation of research findings, implementation of reforms, and product optimization which are being gradually eliminated.

\section{Definitions of Commercialization}

The literature continues to burgeon with multiplying definitions of technology commercialization. In one definition, it involves creating a suitable product with fair price in an attempt to satisfy market demand (Ghazinoori, 2005). In another definition, commercialization is the process of strengthening the linkages between science and economy through technology transfer. Put differently, it is a process through which knowledge and technology are transferred from universities and research centers to industries and new businesses. Commercialization is a complex process influenced by a variety of factors such as infrastructure, technological, social, political, and historical. These factors may either facilitate or impede the commercialization cycle. A combination of above definitions is adopted by present researcher(s). Generally, commercialization can be categorized into three 
different layers of infrastructure, namely technical and market issues, attitudes and policies, and services. There appears to be a widely expressed belief that people's negative attitudes may impede the commercialization cycle. Experience shows that changes in scientific and technological policies of different countries have helped them make a giant leap in technology development. Bahreinin and Shadnam (2007) stated that appropriate policy making can also be used to foster basic change in attitudes and views. There are some significant issues facing the commercialization that require authorities' attention and remedy. For instance, market as the critical success factor in the commercialization process can determine the success or failure of the whole supply chain. If there is a market, companies are to come up with methods for entering and conquering the market and exploring interactions among different elements of it. Otherwise, a market should be created which requires appropriate and specific mechanisms for creating market demands and needs. Some other obstacles to technology commercialization are paucity of researcher participation in creating market opportunities and production environments, time-consuming nature of capital return in technology commercialization, and time-consuming nature of commercialization itself due to which many innovators and entrepreneurs perform insufficient research about the market and, consequently, only one idea from 2,000 becomes successfully commercialized.

Sohn and Moon (2003) attributed difficulties in commercialization to intellectual property, conflicting policies, lack of clarity of capital markets, lack of awareness of customer needs, variability and inaccessibility in technology, paucity of interactions between researchers and executives, inefficiency of commercial management in R \& D companies, need for patent rights for inventors, founders, and personnel; scarcity of funds consistent with the needs of young companies in any stage of growth, and rarity of any thorough model for the commercialization cycle. In fact, commercialization is in fact an art rather than a science.

Investigations have also indicated that the success of $\mathrm{R} \& \mathrm{D}$ commercialization depends on factors such as foreign direct investment capability, effective ownership of R \& D results, entrepreneurial skills, and government plans and policies. 


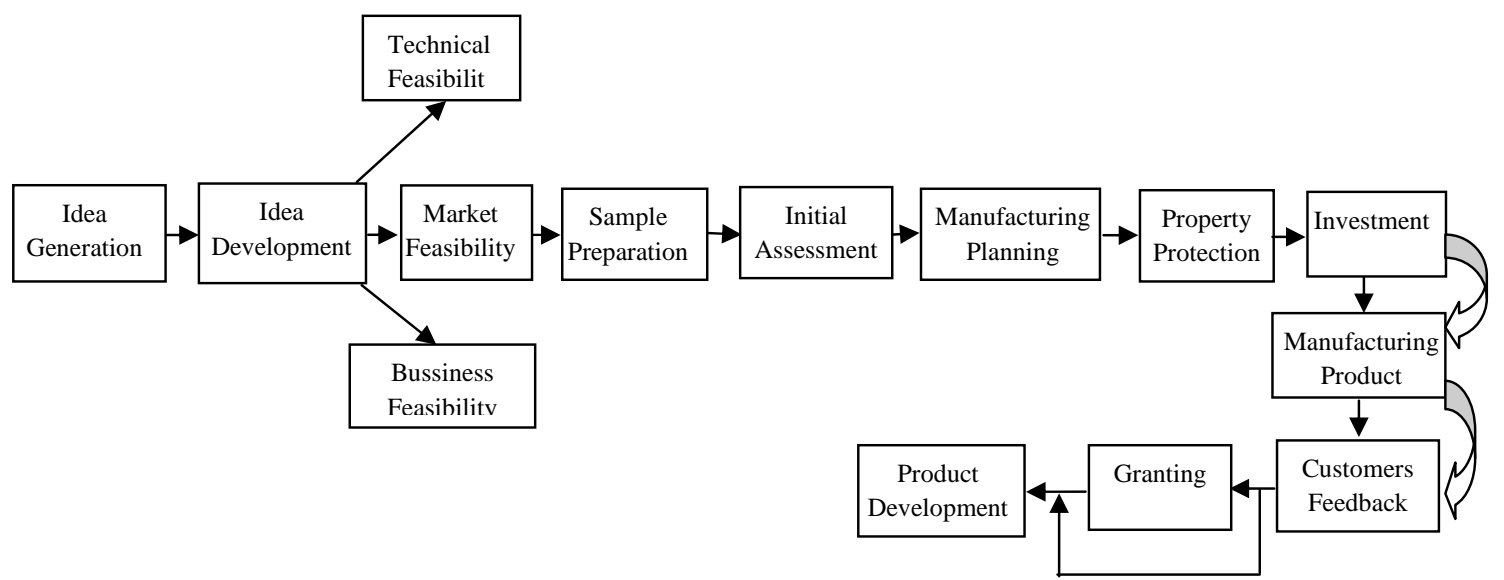

Figure 1. The proposed model of commercialization of technology from idea generation to economic value creation

\section{Stages of Commercialization}

Commercialization happens in thirteen stages the first of which is idea generation. It is the result of intellectual inquiry and stimulation which may originate in encountering environmental factors or studying different resources to resolve ambiguities. In the second stage (developing and nurturing the idea) the idea is confirmed and complemented with regard to structure, conception, and application in order to be adjusted to customer and innovation teams' understanding and perception. The third stage is technical, market, and commercial feasibility study. In this stage the product is meticulously examined to identify its potentials before its breaking into the market. Technical feasibility study refers to the provision of primary materials and equipments for initial production, recruiting and training expert human resources, optimal deployment of technology, and examining current technology levels for implementation purposes, capability for documentation of technology, and ease of the application procedure and training. Market feasibility study includes description of the industry, current market analysis, competition, current demand level, anticipation of future market potential, prediction of future demands, technology pricing strategies, and finally setting market entry policies and estimation of its relevant costs. Ultimately, commercial feasibility study consists of profitability prediction, breakeven analysis, and assessment of sales.

The fourth stage is prototyping products. After the assessment of technical, market, and commercial feasibility the idea should be immediately converted into a physical product in order to prepare the conditions for mass production. In this stage, the idea is designed by using the 3-D simulation software and the prototype is implemented and piloted if there are no design-defect cases and marketing flaws. To receive feedback from customers and identify 
strengths and weaknesses, the product may also be shown in exhibitions or presented in seminars. The next stage is primary evaluation in which the engineering team through access to initial manufacturing plan evaluates the product in terms of technical structure and appearance and takes measures for mass production. It is imperative to mention that here it is essential to get customer feedback so that improvements can be made. The sixth stage is production planning. To facilitate sustained mass production, principled plans should be developed for methods of preparing primary materials and production, marketing processes, super-ordinate and subordinate elements' relations, and constructive interaction with stakeholder organizations and individuals. Protection of intellectual property by means of the intellectual property rights is the next stage. Another way to bring innovations to market is to position the new product through distinguishing it from similar products offered in the market (Fuertes-Callen \& Cuellar-Fernandez, 2014). Hence, serious steps should be taken to record the idea either for legal protection of the ideas of inventor or innovation team and prevention of stealth and forgery or for increasing motivation for the improvement of product status in terms of technology advancement in order to distinguish the product from those of other companies.

The eighth stage of commercialization involves investing. Once safety, capital return, and profitability are ensured, it is time for investors to take serious steps. The ninth stage is product manufacture wherein the idea, having passed through value chain and ensuring product value, becomes practical and produced. The tenth stage in commercialization is technology pursue. After the product is sold, the company should ensure that all customers in their time of need have the ability and skill to use it. In addition, product market should be constantly observed to help identify the gaps between the existing and desired states by increasing productivity through introducing the new technology. In fact, providing effective customer feedback which can help managers to identify their current and also possible future needs can help create product identity. The next stage is provision in licensing agreements. In order to extend technology, obtain profit, and meanwhile conform to intellectual property rights, the rights to manufacture the product are granted to authorized applicants in the form of license agreements. The twelfth stage is technology improvement which is accomplished through receiving customer attitudes and feedback as well as combining multifarious technologies and creating an integrated system. The last but not the least is product development. To retain product status, technology-relevant defects should be corrected and 
options which distinguish the product form similar products should also be taken into account. Such uniqueness also brings about continued profitability.

The focus of this article is the success of commercialization of a good idea which four factors determine, namely team work, hierarchical move from idea generation into the implementation phase of principled plans, disciplines, and perseverance. Team work with the help of the suggested technology commercialization model is the most critical factor since forming an innovation team ensures the feasibility of commercialization.

The most equipped commercialization team is one which is comprised of four characters, i.e., innovator or inventor, investor, technology expert, and entrepreneur (Shaverdi \& Baghdadi, 2010). Inventor is a person who creates and presents a product or process which is either new or better to the existing ones and investor is an individual who invests in properties such as shares, products, and ideas with an aim of gaining profits. In addition, an entrepreneur is a possessor of an idea, an enterprise, or a high-risk investment company that voluntarily accepts the inherent risks associated with starting and growing a new business, product or service. Finally, technology expert is an individual who applies scientific knowledge to practical problems. These four characters should perform their roles effectively apart from any harmful conflicting views and by relying on main goals, i.e., economic growth of the country, job creation, and self-sufficiency.

\section{Concluding Remarks}

In sum, this research article deals with commercialization of research findings which is an essential and inevitable process. Experiences of classical high technology regions (e.g. Silicon Valley) and emerging new technology centers around the world demonstrate that transfer of economically useful scientific knowledge from universities to industries could generate substantial economic growth. In order to economically and socially utilize potentials of research sector, managers and other involved authorities must greatly value ideas and research results through rational decision-making or implementing proper strategies related to the country. This requires organizing the findings of research organizations and universities as well as comprehensive participation of all stakeholders.

The extent to which every organization takes part in $\mathrm{R} \& \mathrm{D}$ activities and product development for surpassing its competitors depends on the strategic position of the organization in demanding market environment. It is customers' needs and wants which instigate creativity and innovation in the development process of a new product. Maintaining 
the current customers and establishing future customers is the reason why every company should invest greatly in development processes. Accordingly, proposing an appropriate model which clarifies the path from idea generation to market entry can aid companies modify the activities of different elements involved in innovation and determine their position and the way that they are supposed to handle the commercialization problem. From an empirical perspective, it is clear that mixed methods techniques, combining qualitative and quantitative methods, micro and macro data, presenting results at multiple levels of analysis, and longitudinal studies, sometimes over considerable periods of time are both feasible and central to a more detailed comprehension of research and technology commercialization.

\section{References}

Bahreini, M. A., \& Shadnam, M. R. (2007). Technology commercialization: How to create value from research and development. Tehran: Baztab Publications.

Dhebar, A. (1996). Speeding high-tech producer, meet the balking consumer. Sloan Management Review, 37(2), 37-49.

Fuertes-Callen, Y. \& Cuellar-Fernandez, B. (2014). What is the role of commercialization and reputation in product innovation success? Innovation: Management, Policy, \& Practice, 16(1), 96-105.

Ghazinoori, S. R. (2005). Strategies and trends for commercialization and marketing of high technologies case study: Nanotechnology in Iran. Paper presented at the second Management of Technology Iranian Conference, Tehran, Iran.

Reamer, A., Iceman, L., \& Youtie, J. (2003). Technology transfer and commercialization: Their role in economic development. Washington, D. C.: U.S. Department of Commerce, Economic Development Administration.

Shaverdi, M. \& Baghdadi, M. (2010). Commercialization of innovative technologies: A guide for successful entrepreneurial innovations (Vol. 1). Tehran: Abgin Rayan Publications.

Sohn, S.Y., \& Moon, T. H. (2003). Structural equation model for predicting technology commercialization success index (TCSI). Journal of Technological Forecasting \& Social Change, 70(9), 885-899.

Varga, A., \& Parag, A. (2009). Academic knowledge transfer and the structure of international research networks. Retrieved from http://www.create2009.europa.eu/

Wu, Y., Welch, E. W., \& Huang, W. (2015). Commercialization of university inventions: Individual and industrial factors affecting licensing of university patents. Technovation, 36(37), 12-25. 